\title{
The Finnish Allergy Programme 2008-2018 works
}

\author{
Tari Haahtela ${ }^{1}$, Erkka Valovirta ${ }^{2}$, Jean Bousquet ${ }^{3,4}$, Mika Mäkelä $^{1}$ and the \\ Allergy Programme Steering Group
}

Affiliations: 'Skin and Allergy Hospital, Helsinki University Hospital, University of Helsinki, Helsinki, Finland. ${ }^{2}$ Dept of Lung Diseases and Clinical Allergology, University of Turku, and Allergy Clinic, Terveystalo, Turku, Finland. ${ }^{3}$ MACVIA-France, Contre les Maladies Chroniques pour un Vieillissement Actif en France, European Innovation Partnership on Active and Healthy Ageing Reference Site, Montpellier, France. ${ }^{4}$ INSERM U 1168 VIMA: Ageing and chronic diseases Epidemiological and public health approaches, Villejuif, Université Versailles Saint-Quentin-en-Yvelines, UMR-S 1168, Montigny le Bretonneux, France.

Correspondence: Tari Haahtela, Skin and Allergy Hospital, Helsinki University Hospital, University of Helsinki, Helsinki, Finland.

E-mail: tari.haahteladahaahtela.fi

@ERSpublications

Revisiting the asthma and allergy paradigms has led to actions relevant to society and healthcare as a whole http://ow.ly/MBG530bPvd6

Cite this article as: Haahtela T, Valovirta E, Bousquet J, Mäkelä M, et al. The Finnish Allergy Programme 2008-2018 works. Eur Respir J 2017; 49: 1700470 [https://doi.org/10.1183/13993003.00470-2017].

\begin{abstract}
Introduction
In Finland (population 5,5 million), a 10-year national campaign to treat allergic diseases was initiated in 2008. It was carefully planned and based on consensus among experts [1-3] because the long-term strategy of allergen avoidance had not reduced the burden or stopped the "epidemic". New insights into immune development in modern, urban societies have challenged conventional thinking. A public health programme has now been implemented, and an avoidance strategy was replaced with a tolerance strategy [4]. This course of action was supported by the Ministry of Social Affairs and Health and the National Institute for Health and Welfare.
\end{abstract}

\section{The burden and the epidemic}

In the early 1990s, asthma was recognised as an inflammatory condition with variable airflow limitation $[5,6]$. The new paradigm emphasised first-line anti-inflammatory treatment [7], which was implemented in practice by the Finnish Asthma Programme 1994-2004. Step 1 involved cutting the disease burden for

The collaborating members of the Allergy Programme Steering Group are as follows: Peter Csonka, Matti Hannuksela, Leena von Hertzen, Juha Jantunen, Paula Kauppi, Krista Kauppinen, Tiina Laatikainen, Irmeli Lindström, Miika Linna, Sirpa Pajunen, Anna Pelkonen, Leena Petman, Mervi Puolanne, Ilkka Repo, Kimmo Saarinen, Alexander Salava, Johannes Savolainen, Erja Tommila, Tuula Vasankari.

Received: March 072017 | Accepted: March 082017

Support statement: From 2008 to 2016, the Ministry of Welfare and Health allocated €60000-65000 annually for educational and coordinating work, which was organised by the Finnish Lung Health Association (Filha), an expert non-governmental organisation. Filha raised private funds of $€ 50000-100000$ per year to carry out the education for more than 20000 healthcare professionals in 2008-2016. For patient education and public communication, three non-governmental patient organisations together received, between 2011 and 2014, an annual payment of $€ 200000$ from Finland's Slot Machine Association (RAY). The main purpose of the government-regulated RAY is to raise funds to promote health and welfare in Finland through gaming operations. Funding information for this article has been deposited with the Crossref Funder Registry.

Conflict of interest: Disclosures can be found alongside this article at erj.ersjournals.com

Copyright @ERS 2017 
individual patients as well as for society by improving early diagnostics and medication [8-10]. The programme served as a model for others to follow [11, 12].

However, the main question remained: how to stop the epidemic? The asthma programme reduced the burden markedly but had no effect on the increased prevalence. Clearly, the true reasons for the increased incidence of allergy and asthma should be better understood in order to move from treatment to prevention. The Karelia Allergy Study, among others, provided some answers [13]. The contrast of prevalence was striking both among children and adults living in Finnish and more rural and traditional Russian Karelia. It seemed likely that the reasons for allergy increase were not so much the new risk factors, characteristic of a modern environment and lifestyle, but the loss of protective factors.

Non-communicable diseases (NCDs), which include allergy, have been increasing everywhere in urban environments. The human immune system seems to be experiencing an adaptation crisis which does not comply with the fast-changing lifestyle and living conditions. Effective gene-environment interaction is the key issue in tolerance development [14]. Reduced connection with natural environments and, for example, the increased use of processed food may have impoverished human microbiota (dysbiosis), caused immune dysfunction (poor tolerance) and led to inappropriate inflammatory responses. The manifested clinical disease is then largely dependent on individual genetic architecture.

Again, there was a place for a paradigm change. The Finnish Allergy Programme 2008-2018 was introduced to test new thinking in practice, and regarded the improvement in allergy health, including asthma health, as step 2.

\section{Programme testing and implementation}

The key messages of the programme are shown in Box 1. They targeted the general population, patients with allergies and asthma and their families, and public-health and patient organisations, as well as experts and authorities. The more specific goals and indicators for healthcare professionals were quantitative, such as that allergy diets should drop by $50 \%$ and asthma emergency visits by $40 \%$ within 10 years. Each of the six goals had specific tasks, tools and evaluation methods [1].

The relevance and acceptance of the messages were tested by email in 2008 among 744 asthma contact persons (response rate 71\%; 38\% were doctors, 62\% nurses, $77 \%$ working in primary care) [15]. The messages were well received. For example, GPs scored strengthen tolerance as 9.1 on a scale from 4 to 10 . However, allergy-management practice left much room for improvement, e.g. the availability of specific immunotherapy was poor (score 5.4).

The expert non-governmental organisation (NGO), the Finnish Lung Health Association (Filha), was responsible for the education of healthcare professionals (doctors, nurses, pharmacists, care-givers). The key issue was to improve allergen tolerance, and simple guidance was provided (table 1). Between 2008 and 2016, more than 20000 professionals participated in the various learning activities. The lay-public has been targeted by three NGOs for: 1) allergy and asthma, 2) respiratory health, and 3) skin disorders. Patient organisations arranged regional education for their key personnel and peer workers; this had a major impact upon direct patient counselling and distribution of educational materials.

Education continued also for the personnel of pharmacies, day-care centres, and schools. From 2009 to 2012, the Association of Finnish Pharmacies produced material and ran campaigns for allergic rhinitis and atopic eczema. The Association of Kindergarten Teachers in Finland planned a pilot campaign called "Go to nature!" for 2014-2015 in southern Karelia, incorporating various outdoor activities into the day-care routine. New guidelines for early childhood education are to be introduced throughout the country.

\section{Contact-person network}

Finland has 21 hospital districts (five university hospitals). Primary healthcare services are provided by about 250 primary care centres, including at least three times as many maternity and child health clinics and approximately 1000 units offering occupational health services, one-third of which are private.

BOX 1 The Finnish Allergy Programme 2008-2018 messages for both healthcare professionals and lay-public; allergy health is promoted

\section{Key messages}

Endorse health, not allergy

Strengthen tolerance

Adopt a new attitude to allergy, and avoid allergens only if mandatory

Recognise and treat severe allergies early; prevent exacerbations

Improve air quality; stop smoking 
TABLE 1 Practical advice for building and improving tolerance as well as preventing symptoms and exacerbations

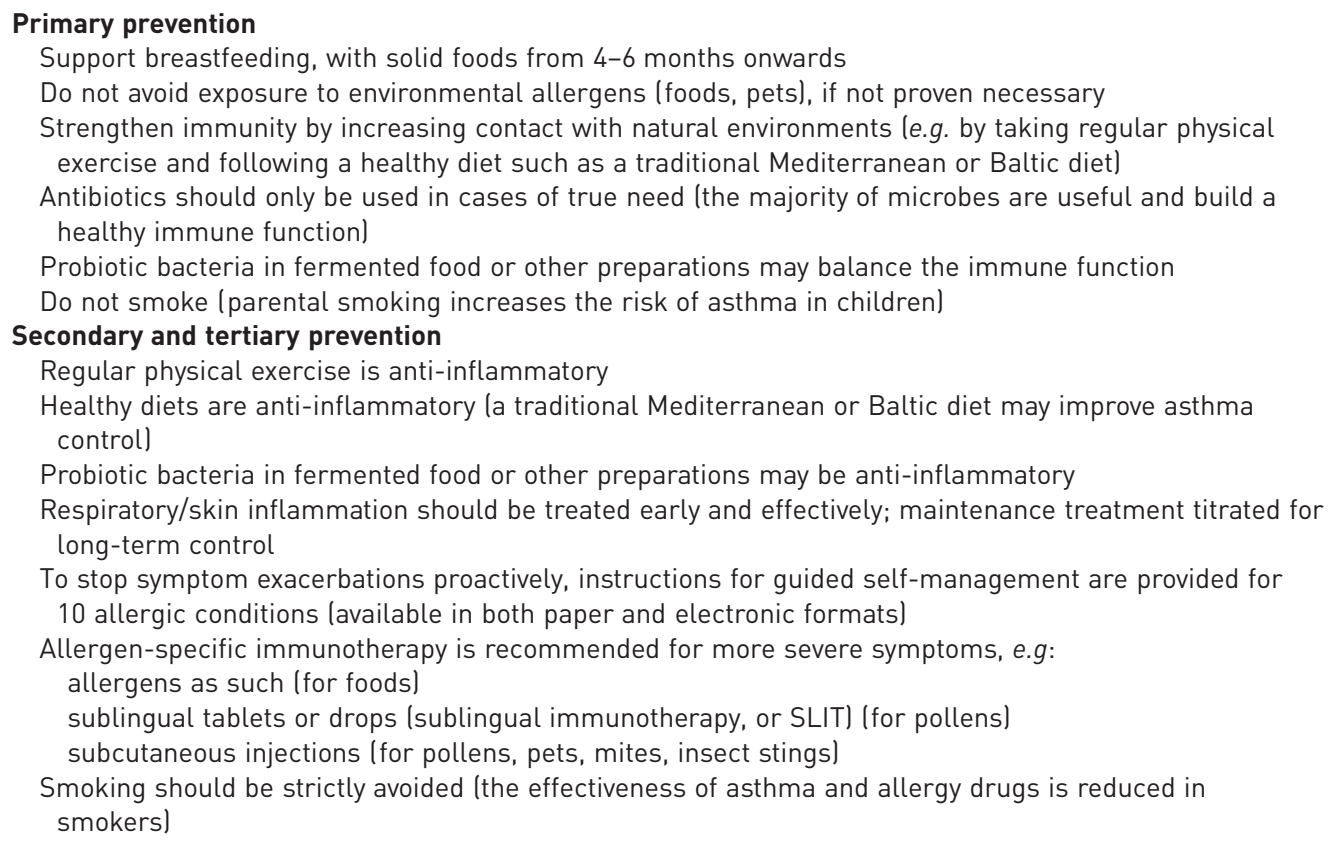

The educational action plan took advantage of the contact-person network created early in the 1994-2004 asthma programme. At baseline, in 2008, about 1500 appointed asthma contact persons (doctors, nurses, pharmacists) were employed in the healthcare sector, originally recruited for the asthma programme. This network was reactivated and strengthened for the allergy campaign. The network has been complemented by some 200 nurses in maternity and child health clinics as well as in schools. Fourteen regional expert allergy groups have begun to coordinate the local implementation of new recommendations via educational activities.

\section{Measuring outcomes}

For outcome evaluation, the Finnish healthcare registers provided invaluable data sources - in particular, the hospital admission register of the National Institute for Health and Welfare and the drug reimbursement register of the Social Insurance Institution of Finland. For occupational diseases, Finland has strict legislation, and verified cases are registered by the Finnish Institute of Occupational Health.

The Finnish anaphylaxis register was established in 2000 at the Skin and Allergy Hospital of the Helsinki University Hospital [16]. Physicians (mostly allergists) from the whole country voluntarily report cases of severe allergic reactions independent of a causative agent. A one-page questionnaire for medical professionals is available on the internet.

Allergy and asthma costs in 2013 were analysed from all data sources in collaboration with government officials.

\section{Are we reaching the goals?}

The mid-term outcome is summarised in table 2. The burden of allergy and asthma has been further reduced since the beginning of the asthma programme [17]. In the 2000s, asthma emergency visits decreased by $46 \%$ (children 62\%) and hospital days by $67 \%$. According to a country-wide pharmacy barometer survey, self-reported asthma has become a milder disease or a better controlled disease [18]. At the start of the Finnish asthma programme in 1994, it was estimated that $20 \%$ of the patients had a severe (or uncontrolled) condition. This figure decreased to $10 \%$ in 2001 and to $4 \%$ in 2010 . In 2016 this figure was 2.5\% (P. Kauppi, J. Jantunen; unpublished, personal communication). Compared with the 2001 and 2010 cohorts, emergency visits during the previous year had dropped by $86 \%$ and hospitalisations by $88 \%$. Asthma mortality has been very low: in 2006-2013, on average seven annual deaths (range 3-12) under the age of 60 years. 


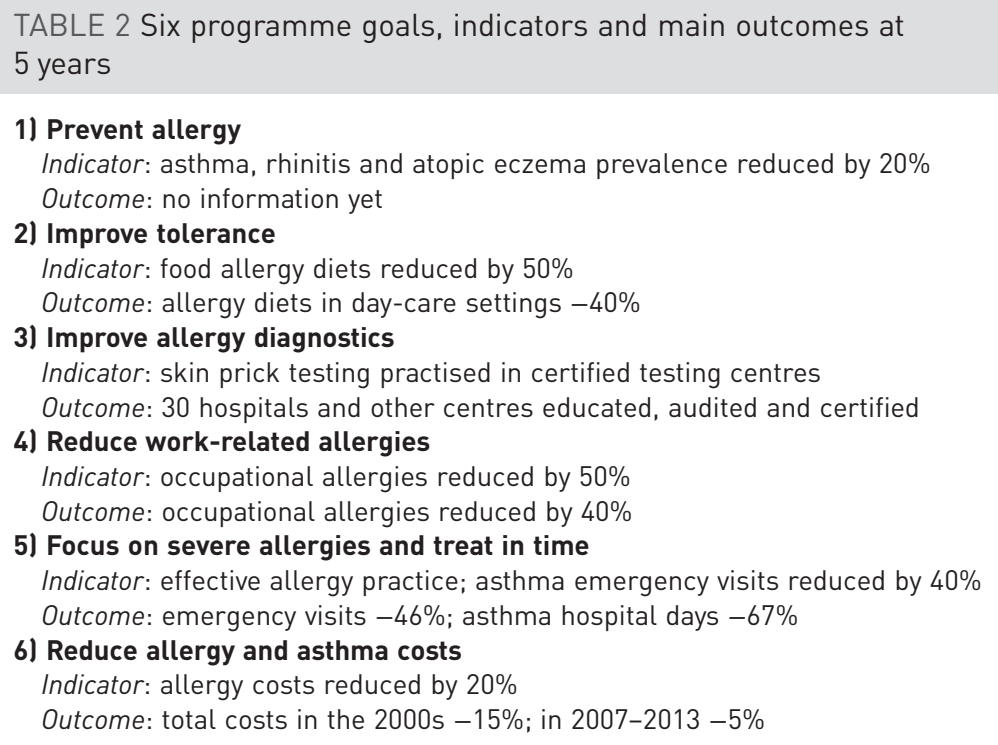

In 13 years (2000-2013), the number of emergency visits caused by anaphylaxis almost doubled from 297 to 582 cases. In children (1999-2011), hospitalisations due to allergic reactions increased (from 7.8 to 15.8 per 100000 person-years), but the numbers were somewhat lower than those for Sweden [19]. The anaphylaxis campaign has improved awareness and explains much of the increase. Only a few anaphylaxis-related deaths per year occurred in 1996-2013, and no deaths occurred in children [20].

In the Helsinki capital region, 40 Finnish day-care centres were educated to follow simple pragmatic allergy guidelines [21]. In 2013-2015, the prevalence of allergy diets decreased $43 \%$, from $7.6 \%$ to $4.3 \%$. Parent-reported allergies to nuts, fruits and vegetables decreased among first graders in the first year of elementary schools [22].

In 2007-2013, verified occupational allergies (asthma, allergic rhinitis, allergic contact dermatitis) fell by $40 \%$, as registered by the National Institute of Occupational Health. The reduction could not be explained by changes in the workforce.

In the first decade of the 2000s, the direct allergy and asthma costs, together with costs for disability pensions, fell by15\% [17]. During the early years of the programme (2007-2013), these costs have fallen from $€ 386$ million to 367 million (-5\%). Asthma costs decreased by $9 \%$ and comprised $63 \%$ of all costs.

\section{Conclusions}

There are no reports of nationwide, comprehensive public health programmes for allergic disorders that include set goals and systematic follow-up. The mid-term results of the ongoing Finnish campaign indicate that the burden of allergic conditions in that particular society has started to decline. Focusing on severe allergies and emphasising allergy health rather than mild problems has encouraged a more efficient use of healthcare resources. It also seems that prevalences are levelling off. However, it is too early to give credit to the programme for any biological changes in the population.

The outcome of the present real-life intervention, including all Finnish citizens, without effective controls is also open to criticism. This should not, however, prevent medical communities from taking reasonable action to improve public health, in this case lessening the disability and costs resulting from allergy and asthma. Inadequate allergy care seems to be a global problem and leads to delays in patient management and poor outcomes [23].

Revisiting the asthma and allergy paradigms has led to actions relevant to society and healthcare as a whole.

\section{References}

1 Haahtela T, von Hertzen L, Mäkelä M, et al. Finnish Allergy Programme 2008-2018--time to act and change the course. Allergy 2008; 63: 634-645.

2 Bousquet J, Bieber T, Fokkens W, et al. In Allergy, 'A new day has begun'. Allergy 2008; 63: 631-633.

3 Pelkonen AS, Kuitunen M, Dunder T, et al. Allergy in children: practical recommendations of the Finnish Allergy Programme 2008-2018 for prevention, diagnosis, and treatment. Pediatr Allergy Immunol 2012; 23: 103-116. 

2008-2018: emphasis on prevention and endorsing tolerance. Allergy 2009; 64: 678-701.

5 Laitinen LA, Heino M, Laitinen A, et al. Damage of the airway epithelium and bronchial reactivity in patients with asthma. Am Rev Respir Dis 1985; 131: 599-606.

6 Bousquet J, Chanez P, Lacoste JY, et al. Eosinophilic inflammation in asthma. N Engl J Med 1990; 323: 1033-1039.

7 Haahtela T, Järvinen M, Kava T, et al. Comparison of a $\beta 2$-agonist, terbutaline, with an inhaled corticosteroid, budesonide, in newly detected asthma. N Engl J Med 1991; 325: 388-392.

8 Haahtela T, Tuomisto LE, Pietinalho A, et al. A 10 year asthma programme in Finland: major change for the better. Thorax 2006; 61: 663-670.

9 Nermes M, Vanto T, Elenius V, et al. Lasten astman miniohjelma toteutuu tyydyttävästi [Adherence to national childhood asthma programme is satisfactory]. Finn Med J 2005; 60: 2805-2809.

10 Haahtela T, Herse F, Karjalainen J, et al. The Finnish experience to save asthma costs by improving care in 19872013. J Allergy Clin Immunol 2017; 139: 408-414.

11 Selroos O, Kupczyk M, Kuna P, et al. National and regional asthma programmes in Europe. Eur Respir Rev 2015; 24: 474-483

12 Asher I, Haahtela T, Selroos O, et al. Global Asthma Network survey suggests more national asthma strategies could reduce burden of asthma. Allergol Immunopathol (Madr) 2017; 45: 105-114.

13 Haahtela T, Laatikainen T, Alenius $\mathrm{H}$, et al. Hunt for the origin of allergy - comparing the Finnish and Russian Karelia. Clin Exp Allergy 2015; 45: 891-901.

14 Garn H, Bahn S, Baune BT, et al. Current concepts in chronic inflammatory diseases: interactions between microbes, cellular metabolism, and inflammation. J Allergy Clin Immunol 2016; 138: 47-56.

15 Kauppi P, Kämäräinen J, Haahtela T. Kansallinen allergiaohjelma vaatii koulutusta ja työkaluja (Allergy Programme clearly necessary - training and tools needed). Finn Med J 2010; 43: 3515-3520.

16 Mäkinen-Kiljunen S, Haahtela T. Eight years of severe allergic reactions in Finland. A register-based report. World Allergy Organ J 2008; 1:184-189.

17 Haahtela T, Valovirta E, Hannuksela M, et al. Kansallinen allergiaohjelma puolivälissä - suunnan muutos tuo tuloksia [Finnish nationwide allergy programme at mid-term - Change of direction producing results]. Finn Med J 2015; 70: 2165-2172.

18 Kauppi P, Peura S, Salimäki J, et al. Reduced severity and improved control of self-reported asthma in Finland during 2001-2010. Asia Pac Allergy 2015; 5: 32-39.

19 Kivistö JE, Protudjer JL, Karjalainen J, et al. Hospitalizations due to allergic reactions in Finnish and Swedish children during 1999-2011. Allergy 2016; 71: 677-683.

20 Kivistö JE, Dunder T, Protudjer JL, et al. Adult but no pediatric anaphylaxis-related deaths in the Finnish population from 1996 to 2013. J Allergy Clin Immunol 2016; 138: 630-632.

21 Erkkola M, Saloheimo T, Hauta-alus H, et al. LILLA study group. Burden of allergy diets in Finnish day care reduced by change in practices. Allergy 2016; 71: 1453-1460.

22 Järvenpää J, Paassilta M, Salmivesi S, et al. Stability of parent reported food allergy in six and 7-year-old children: the first 5 years of the Finnish allergy programme. Acta Paediatr 2014; 103: 1297-1300.

23 Diwakar L, Cummins C, Lilford R, et al. Systematic review of pathways for the delivery of allergy services. BMJ Open 2017; 7: e012647. 